\title{
Effects of Hyperbilirubinemia on Cerebrocortical Electrical Activity in Newborns
}

\author{
DOLUNAY GÜRSES, ILKNUR KİLIÇ, AND TÜRKER ŞAHINER \\ Departments of Pediatrics [D.G., I.K.] and Neurology [T.Ş.], Pamukkale University Faculty of Medicine, \\ Denizli, Turkey
}

\begin{abstract}
ABST
In our study, cerebrocortical electrical activity was recorded
as an indicator of bilirubin neurotoxicity. Bilirubin especially
affects the thalamus and cerebral cortex. Inasmuch as rhythmic
oscillations on the EEG arise from the interaction between cortex
and thalamus, electrophysiologic effects of bilirubin on the rhyth-
mic oscillations with long-term postnatal age were investigated.
Brain maturation was also analyzed with power spectral analysis
quantitatively. For this purpose, 141 EEG records were taken (in
the first week, 15 th d, at the end of the first month, and at the
third month) from 17 infants with hyperbilirubinemia and 22
healthy infants. In all records, the major frequency component
was formed by the delta frequency in both groups. In the first
records of the hyperbilirubinemia group, the delta frequency was
higher than the control group; however the theta, alpha, and beta
frequencies and the amplitude levels were lower $(p<0.001)$.
These changes were found to be significantly correlated with the
bilirubin levels ( $p<0.001)$. On the 15 th d the amplitude of the
\end{abstract}
Hyperbilirubinemia is one of the most common problems during the neonatal period. Bilirubin encephalopathy is a neurologic syndrome resulting from the deposition of bilirubin in brain cells. A characteristic yellow color change by unconjugated bilirubin is seen, particularly in the corpus subthalamicum, hippocampus, thalamus, globus pallidus, putamen, cranial nerve nuclei, and cerebral cortex (1-4). Yellow staining of the brain has also been observed in infants dying without clinical symptoms of kernicterus, and in whom only moderately elevated serum bilirubin values had been noted (5). In addition, bilirubin damages nonpigmented areas. Loss of neurons, reactive gliosis, and atrophy of involved fiber systems are found in late disease $(3,4)$. Bilirubin inhibits oxidative phosphorylation and respiration in the mitochondria of the brain (6).

The EEG has been used to study the maturation of the brain as the infant grows in the first year of life, as well as to identify abnormalities in cerebral electrical activity including delays of

Received January 20, 2001; accepted February 15, 2002.

Correspondence and reprint requests: Dolunay Gürses, M.D., Department of Pediatrics, Pamukkale University Faculty of Medicine, Denizli, Turkey; e-mail: dolunayk@ yahoo.com

DOI: 10.1023/01.PDR.0000016662.84289.BA hyperbilirubinemia group increased to similar levels as the control group. At the frequency bands of delta and theta, there were significant changes related to postnatal age $(p<0.001)$. In all cerebral regions, the delta frequency decreased and the theta frequency increased with age. However, in the hyperbilirubinemia group the delta frequency was higher, the theta frequency was lower, and the changes between the groups disappeared in the third month despite the differences at all regions of the brain. In terms of the vertex, k complex, and sleep spindle, there were no differences between both groups in the third month $(p>0.05)$. We conclude that hyperbilirubinemia affects the cerebrocortical electrical activity but appears to be time limited. (Pediatr Res 52: 125-130, 2002)
Abbreviation
G6PD, glucose- 6-phosphate dehydrogenase

the normal maturation sequence (7). In this study, the effect of hyperbilirubinemia on brain maturation was investigated by EEG, and brain maturation was also analyzed with power spectral analysis.

\section{METHODS}

Seventeen infants with unconjugated hyperbilirubinemia and 22 healthy infants from Pamukkale University Hospital Neonatal Care Unit were prospectively recruited for a study aiming to observe normal maturation of EEG patterns. No infant suffered from major medical illness or required ventilatory assistance during the neonatal period. All of the babies were between 38 and 42 wk of gestation and were appropriate for gestational age according to the Dubowitz score (8). All infants were developmentally normal in the first 3 mo of life either by neurodevelopmental testing or parental report. All of the babies' families were informed about the study, and written consent was signed by all of them. The institutional review board approved the study.

Babies with unconjugated hyperbilirubinemia constituted the study group, and the bilirubin levels were above the phototherapy limit (9). All of the babies were monitored for 
bilirubin levels four times a day. Babies whose bilirubin levels were under phototherapy limits were recruited as a control group. All of the babies in the study and control groups were asymptomatic. Infants whose mothers had diabetes mellitus, eclampsia, or preeclampsia and infants whose Apgar scores were low were excluded. The babies did not have respiratory and cardiac diseases or congenital malformations.

Each infant received an initial EEG examination in the first week (between 48 and $90 \mathrm{~h}$ of life) because the bilirubin levels were peak values before the treatment. After treatment bilirubin values did not increase. Then serial EEGs were performed on the 15th $\mathrm{d}$ and in the first and third months. Studies were performed in an environmentally controlled setting in which sound, light, humidity, and tactile stimulation were carefully monitored. All infants were studied during sleep in a prone position on an open bed. No infant received medication. For each recording, the infant was admitted to the hospital before $1000 \mathrm{~h}$. After a routine pediatric examination, EEG was recorded at least $1 \mathrm{~h}$ in only quiet sleep periods. EEG apparatus was produced by Medelec Profile Digital EEG Systems (U.K).

In the first three EEG recordings, digitized data were collected from 11 cerebral electrodes, placed according to the modified International $10 / 20$ system for neonates $\left(\mathrm{Fp}_{1}, \mathrm{Fp}_{2}, \mathrm{C}_{3}\right.$, $\mathrm{C}_{4} \mathrm{Cz}, \mathrm{T}_{3}, \mathrm{~T}_{4}, \mathrm{O}_{1}, \mathrm{O}_{2}, \mathrm{~A}_{1}$, and $\mathrm{A}_{2}$ ). Twelve channels were used for recording $\left(\mathrm{Fp}_{1}-\mathrm{C}_{3}, \mathrm{C}_{3}-\mathrm{O}_{1}, \mathrm{Fp}_{2}-\mathrm{C}_{4}, \mathrm{C}_{4}-\mathrm{O}_{2}, \mathrm{Fp}_{1}-\mathrm{T}_{3}, \mathrm{Fp}_{2}-\right.$ $\mathrm{T}_{4}, \mathrm{~T}_{3}-\mathrm{O}_{1}, \mathrm{~T}_{4}-\mathrm{O}_{2}, \mathrm{~T}_{3}-\mathrm{C}_{3}, \mathrm{C}_{4}-\mathrm{T}_{4}, \mathrm{C}_{3}-\mathrm{Cz}$, and $\left.\mathrm{Cz}-\mathrm{C}_{4}\right)$. Eight noncerebral channels and an event-marker program recorded viscerosomatic measures (two channels of electro-oculogram, one channel of submental electromyogram, one channel of respirogram, one channel of ECG, one channel of oxygen saturation, and two channels of skin and rectal temperatures). In the third month, 21 cerebral electrodes were placed according to the international $10 / 20$ system (10), and the same noncerebral channels were used. Records were performed at high-frequency filter of $70 \mathrm{~Hz}$, low-frequency filter of $0.16 \mathrm{~Hz}$, and sensitivity of $100 \mu \mathrm{V} / \mathrm{mm}$. The signals were recorded on hard disk and transferred to CD-ROM for storage. Carefully selected artifact-free 10-s periods of each EEG from the beginning, in the middle, and at the end were analyzed. Rough digital EEG data were transformed into power spectral analysis by software, which was written by Medelec Corporation. Analyzed results were given in four different frequency bands [delta $(\theta), 0-4 \mathrm{~Hz}$; theta $(\delta), 4-8 \mathrm{~Hz}$; alpha $(\alpha), 8-13 \mathrm{~Hz}$; and beta $(\beta), 13-22 \mathrm{~Hz}$ ] as percentages of each frequency band. We collected these data in five different regions for every patient $\left(\mathrm{Fp}_{1}-\mathrm{C}_{3}, \mathrm{C}_{3}-\mathrm{O}_{1}, \mathrm{Fp}_{2}-\mathrm{C}_{4}, \mathrm{C}_{4}-\mathrm{O}_{2}\right.$, and $\left.\mathrm{Cz}-\mathrm{C}_{4}\right)$, and it was compared with control group values. Mean amplitude values were obtained from every channel. In the third month, sleep spindles, vertex, and $\mathrm{k}$ complex were analyzed.

Total and direct bilirubin concentrations were determined using the modified Jendrassic Grof method in the Hitachi 902 automatic analyzer (Abbott Laboratories,U.S.A.).

Statistical analyses were performed by Systat statistical software (version 7.0 for Windows; SPSS Inc, Chicago, IL, U.S.A.) The $t$ test, $\chi^{2}$, repeated-measures ANOVA, Pearson correlation, and linear regression analysis were used for data analyses. Statistical significance was taken at $p<0.05$. All data are presented as the mean $\pm \mathrm{SD}$.

\section{RESULTS}

There were no differences between the two groups in sex, Apgar score, conceptual age, weight, length, and head circumference $(p>0.05)$. The study group consisted of 17 babies ( 7 girls, 10 boys). There were 22 babies in the control group (10 girls, 12 boys). Apgar scores were $9-10$ in the first minute and 10 in the 10th min. Bilirubin levels in the study and control groups were $22.4 \pm 5.4 \mathrm{mg} / \mathrm{dL}$ (range, $16.2-33 \mathrm{mg} / \mathrm{dL}$ ) and 7.7 $\pm 3.2 \mathrm{mg} / \mathrm{dL}$ (range, $2-13.3 \mathrm{mg} / \mathrm{dL}$ ), respectively. There was a significant difference between the bilirubin levels of the two groups $(p<0.001$; Table 1$)$. On the 15th d, bilirubin levels were under the pathologic bilirubin levels, and there was no difference between the two groups $(p>0.05)$.

We detected $\mathrm{Rh}$ immunization $(n=1)$, ABO immunization $(n=3)$, urinary tract infection $(n=1)$, and deficiency of the G6PD $(n=3)$ in the study group. Direct Coombs test was positive only for the case of Rh immunization. In the patients who had higher bilirubin levels than $26 \mathrm{mg} / \mathrm{dL}$, Rh immunization $(n=1), \mathrm{ABO}$ immunization $(n=1)$, and G6PD deficiency $(n=2)$ were found. We could not detect any cause in one patient.

Delta frequency was the major frequency component during the procedure in the both groups. The delta frequency activity decreased and other frequency bands increased with age. The data for serial EEG records are shown in Tables 2-6.

When we compared the results of the first records in both groups, delta frequency in the study group was higher, but alpha, theta, and beta frequencies and amplitude levels were significantly lower than those in the control group $(p<0.001)$. We observed that the amplitude levels in the study group of the second records were similar with those in the control group, and the amplitude levels were found to be similar during the 3-mo period in both groups ( $p>0.05$; Table 2).

There were significant changes related to postnatal age in the frequencies of delta and theta $(p<0.001)$. In all cerebral regions, the delta frequency decreased and the theta frequency increased with age $(p<0.001)$. However, in the hyperbilirubinemia group the delta frequency was higher and the theta frequency was lower than those in the control group $(p<$ $0.05)$.

We found that alpha and beta frequencies in the study group were lower than those in the control group in all records $(p<$ $0.05)$. In the control group, a mild increase in alpha frequency with postnatal age, which was not statistically significant, was detected. However, in the study group, the difference was significant between the first and second tests $(p<0.05)$. The differences in the beta frequency with postnatal age were significant for only left anterior region $(p<0.05)$. We could not explain the statistically significant changes for beta fre-

Table 1. Study and control groups (mean $\pm S D)$

\begin{tabular}{lccc}
\hline & Hyperbilirubinemia & Control & $p$ \\
\hline Conceptual age (wk) & $40.1 \pm 2.7$ & $39.6 \pm 0.8$ & $>0.05$ \\
Length $(\mathrm{cm})$ & $50.3 \pm 1.2$ & $50.1 \pm 1.2$ & $>0.05$ \\
Head circumference (cm) & $34.4 \pm 1$ & $34.7 \pm 0.9$ & $>0.05$ \\
Weight $(\mathrm{g})$ & $3252 \pm 462$ & $3443 \pm 399$ & $>0.05$ \\
Bilirubin (mg/dL) & $22.4 \pm 5.4$ & $7.7 \pm 3.2$ & $<0.001$ \\
\hline
\end{tabular}


Table 2. Amplitudes in serial EEG records (mean $\pm S D$ )

\begin{tabular}{|c|c|c|c|c|c|}
\hline Amplitude $(\mu \mathrm{v})$ & $1 \mathrm{st}$ test & 2nd test & 3rd test & 4th test & $p^{*}$ \\
\hline Hyperbilirubinemia & $1130 \pm 151$ & $1447 \pm 185$ & $1436 \pm 118$ & $1425 \pm 97$ & $<0.001$ \\
\hline Control & $1415 \pm 170$ & $1407 \pm 170$ & $1434 \pm 113$ & $1357 \pm 112$ & $>0.05$ \\
\hline$p^{* *}$ & $<0.001$ & $>0.05$ & $>0.05$ & $>0.05$ & \\
\hline
\end{tabular}

* Indicates statistical analyses of serial records in each groups.

** Indicates statistical analyses of two groups.

Table 3. Delta frequencies in serial EEG records (mean $\pm S D$ )

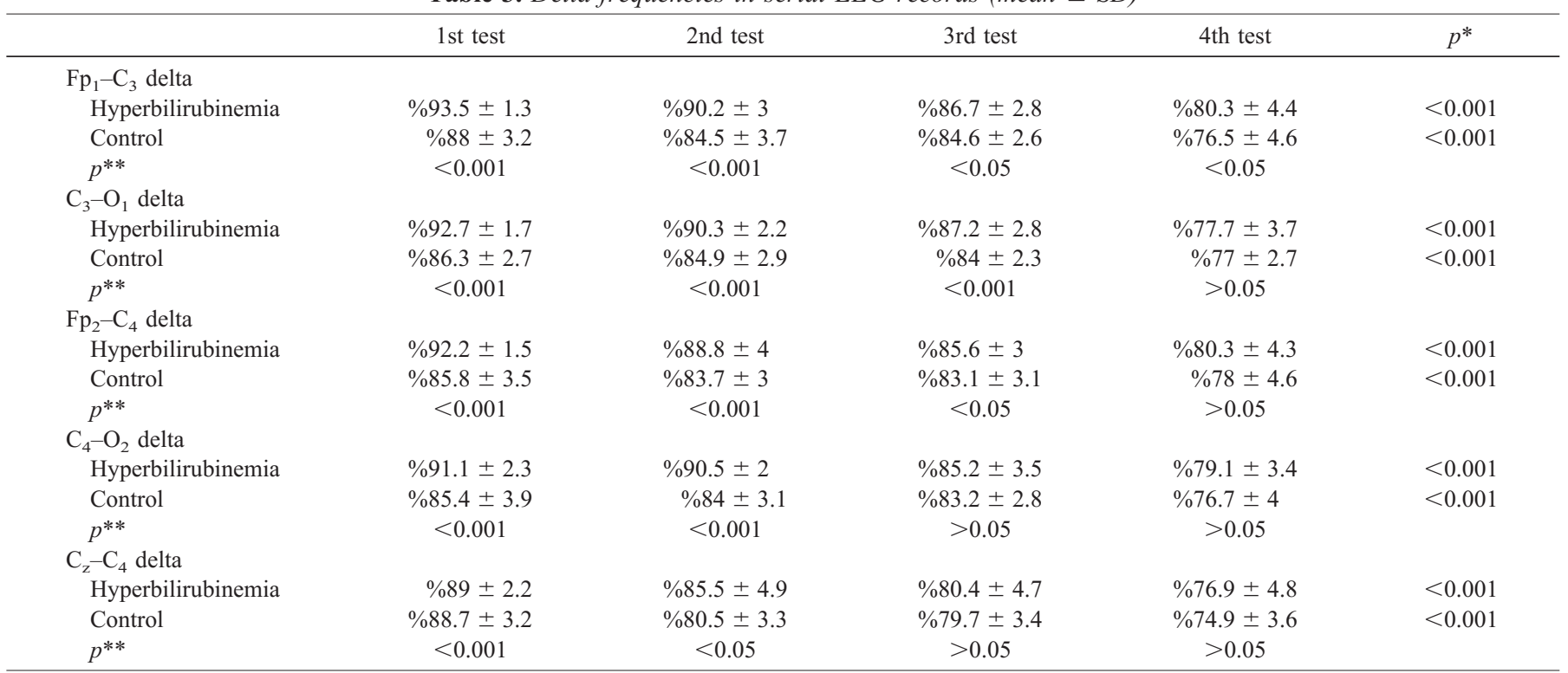

* Indicates statistical analyses of serial records in each groups.

** Indicates statistical analyses of two groups.

Table 4. Theta frequencies in serial EEG records (mean $\pm S D$ )

\begin{tabular}{|c|c|c|c|c|c|}
\hline & 1 st test & 2nd test & 3rd test & 4 th test & $p^{*}$ \\
\hline \multicolumn{6}{|l|}{$\mathrm{Fp}_{1}-\mathrm{C}_{3}$ theta } \\
\hline Hyperbilirubinemia & $\% 4.2 \pm 1$ & $\% 6.4 \pm 2$ & $\% 9.2 \pm 2.6$ & $\% 15 \pm 3.6$ & $<0.001$ \\
\hline Control & $\% 7.7 \pm 2.2$ & $\% 10.7 \pm 2.3$ & $\% 10.6 \pm 2.2$ & $\% 21.3 \pm 15.3$ & $<0.001$ \\
\hline \multicolumn{6}{|l|}{$\mathrm{C}_{3}-\mathrm{O}_{1}$ theta } \\
\hline Hyperbilirubinemia & $\% 4.6 \pm 1$ & $\% 6 \pm 1.8$ & $\% 8.8 \pm 2.7$ & $\% 18.2 \pm 3.8$ & $<0.001$ \\
\hline Control & $\% 8.5 \pm 2.4$ & $\% 10 \pm 2.3$ & $\% 11.4 \pm 2.7$ & $\% 21.2 \pm 14$ & $<0.001$ \\
\hline Hyperbilirubinemia & $\% 5.2 \pm 1.4$ & $\% 6.9 \pm 2.6$ & $\% 10.1 \pm 3$ & $\% 14.4 \pm 3.8$ & $<0.001$ \\
\hline Control & $\% 9.3 \pm 2.3$ & $\% 11.1 \pm 2.4$ & $\% 12 \pm 2.3$ & $\% 20.5 \pm 16$ & $<0.001$ \\
\hline$p^{* *}$ & $<0.001$ & $<0.001$ & $<0.05$ & $>0.05$ & \\
\hline \multicolumn{6}{|l|}{$\mathrm{C}_{4}-\mathrm{O}_{2}$ theta } \\
\hline Hyperbilirubinemia & $\% 5.4 \pm 1.7$ & $\% 5.6 \pm 1.8$ & $\% 10.4 \pm 3.1$ & $\% 16.7 \pm 3.8$ & $<0.001$ \\
\hline Control & $\% 9.4 \pm 2.9$ & $\% 11 \pm 2.3$ & $\% 12.2 \pm 2.1$ & $\% 22 \pm 13.8$ & $<0.001$ \\
\hline$p^{* *}$ & $<0.001$ & $<0.001$ & $>0.05$ & $>0.05$ & \\
\hline
\end{tabular}

* Indicates statistical analyses of serial records in each groups.

** Indicates statistical analyses of two groups.

quency in the $\mathrm{Fp}_{1}-\mathrm{C}_{3}$ channel. There were statistically significant differences between serial records of the study group for delta and theta frequencies $(p<0.05)$. However, the differences were usually in the first and third months in the control group $(p<0.05)$.

During the first tests, we found statistically significant negative correlation between bilirubin levels and theta, alpha, and beta frequencies and amplitude in all channels $(r$ values for theta frequency in $\mathrm{Fp}_{1}-\mathrm{C} 3, \mathrm{C}_{3}-\mathrm{O}_{1}, \mathrm{Fp}_{2}-\mathrm{C}_{4}, \mathrm{C}_{4}-\mathrm{O}_{2}, \mathrm{C}_{3}-\mathrm{C}_{\mathrm{Z}}$, and $\mathrm{C}_{\mathrm{z}}-\mathrm{C}_{4}$ channels, $-0.60,-0.61,-0.64,-0.63,-0.66$, and -0.74 , respectively; alpha frequency, $-0.60,-0.77,-0.61$, $-0.62,-0.51$, and -0.57 , respectively; beta frequency, $-0.50,-0.61,-0.45,-0.50,-0.48$, and -0.39 , respectively; and amplitude, -0.77$)$, but significantly positive correlation 
Table 5. Alpha frequencies in serial EEG records (mean $\pm S D$ )

\begin{tabular}{|c|c|c|c|c|c|}
\hline & $1 \mathrm{st}$ test & 2 nd test & 3rd test & 4th test & $p^{*}$ \\
\hline \multicolumn{6}{|l|}{$\mathrm{Fp}_{1}-\mathrm{C}_{3}$ alpha } \\
\hline Hyperbilirubinemia & $\% 1.3 \pm 0.3$ & $\% 2 \pm 0.7$ & $\% 2.4 \pm 0.6$ & $\% 2.6 \pm 0.5$ & $<0.001$ \\
\hline Control & $\% 2.5 \pm 0.8$ & $\% 3 \pm 1.1$ & $\% 2.9 \pm 1.4$ & $\% 3.7 \pm 3.1$ & $>0.05$ \\
\hline \multicolumn{6}{|l|}{$\mathrm{C}_{3}-\mathrm{O}_{1}$ alpha } \\
\hline Hyperbilirubinemia & $\% 1.7 \pm 0.5$ & $\% 2 \pm 0.5$ & $\% 2.5 \pm 0.7$ & $\% 2.6 \pm 0.5$ & $<0.001$ \\
\hline Control & $\% 2.9 \pm 0.4$ & $\% 2.7 \pm 0.7$ & $\% 2.7 \pm 0.6$ & $\% 3.8 \pm 4.1$ & $>0.05$ \\
\hline Hyperbilirubinemia & $\% 1.5 \pm 0.4$ & $\% 2.5 \pm 0.9$ & $\% 2.4 \pm 0.5$ & $\% 3.2 \pm 1.4$ & $<0.001$ \\
\hline Control & $\% 2.8 \pm 0.9$ & $\% 2.9 \pm 0.8$ & $\% 2.8 \pm 0.9$ & $\% 3.6 \pm 2.4$ & $>0.05$ \\
\hline$p^{* *}$ & $<0.05$ & $>0.05$ & $>0.05$ & $>0.05$ & \\
\hline \multicolumn{6}{|l|}{$\mathrm{C}_{4}-\mathrm{O}_{2}$ alpha } \\
\hline Hyperbilirubinemia & $\% 2.2 \pm 0.8$ & $\% 1.9 \pm 0.6$ & $\% 2.7 \pm 0.8$ & $\% 2.6 \pm 0.8$ & $<0.05$ \\
\hline Control & $\% 3 \pm 0.8$ & $\% 2.8 \pm 0.8$ & $\% 2.9 \pm 0.7$ & $\% 3.6 \pm 4.8$ & $>0.05$ \\
\hline$p^{* *}$ & $<0.001$ & $>0.05$ & $>0.05$ & $>0.05$ & \\
\hline
\end{tabular}

* Indicates statistical analyses of serial records in each groups.

** Indicates statistical analyses of two groups.

Table 6. Beta frequencies in serial EEG records (mean $\pm S D$ )

\begin{tabular}{|c|c|c|c|c|c|}
\hline & 1 st test & 2 nd test & 3rd test & 4th test & $p^{*}$ \\
\hline \multicolumn{6}{|l|}{$\mathrm{Fp}_{1}-\mathrm{C}_{3}$ beta } \\
\hline Hyperbilirubinemia & $\% 0.9 \pm 0.3$ & $\% 1.4 \pm 0.7$ & $\% 1.5 \pm 0.8$ & $\% 2.3 \pm 1$ & $<0.001$ \\
\hline Control & $\% 1.8 \pm 0.7$ & $\% 2.3 \pm 1$ & $\% 1.7 \pm 0.7$ & $\% 2.6 \pm 1.4$ & $<0.05$ \\
\hline \multicolumn{6}{|l|}{$\mathrm{C}_{3}-\mathrm{O}_{1}$ beta } \\
\hline Hyperbilirubinemia & $\% 1.3 \pm 0.6$ & $\% 1.8 \pm 0.9$ & $\% 1.6 \pm 0.5$ & $\% 1.6 \pm 0.4$ & $>0.05$ \\
\hline Control & $\% 2.3 \pm 0.7$ & $\% 2.2 \pm 0.8$ & $\% 1.7 \pm 0.7$ & $\% 2.1 \pm 0.7$ & $>0.05$ \\
\hline Hyperbilirubinemia & $\% 1.2 \pm 0.6$ & $\% 2 \pm 0.8$ & $\% 1.9 \pm 0.5$ & $\% 2.3 \pm 1$ & $>0.05$ \\
\hline Control & $\% 2.1 \pm 0.8$ & $\% 2.3 \pm 0.9$ & $\% 2 \pm 0.8$ & $\% 2.3 \pm 0.8$ & $>0.05$ \\
\hline$p^{* *}$ & $<0.001$ & $>0.05$ & $>0.05$ & $>0.05$ & \\
\hline \multicolumn{6}{|l|}{$\mathrm{C}_{4}-\mathrm{O}_{2}$ beta } \\
\hline Hyperbilirubinemia & $\% 1.6 \pm 0.6$ & $\% 1.6 \pm 0.6$ & $\% 1.9 \pm 0.7$ & $\% 1.8 \pm 0.5$ & $>0.05$ \\
\hline Control & $\% 2.3 \pm 0.9$ & $\% 2.2 \pm 0.8$ & $\% 1.9 \pm 0.5$ & $\% 1.9 \pm 0.9$ & $>0.05$ \\
\hline$p^{* *}$ & $<0.05$ & $>0.05$ & $>0.05$ & $>0.05$ & \\
\hline
\end{tabular}

* Indicates statistical analyses of serial records in each groups.

** Indicates statistical analyses of two groups.

was found with delta frequency $(r$ values for delta frequency in $\mathrm{Fp}_{1}-\mathrm{C}_{3}, \mathrm{C}_{3}-\mathrm{O}_{1}, \mathrm{Fp}_{2}-\mathrm{C}_{4}, \mathrm{C}_{4}-\mathrm{O}_{2}, \mathrm{C}_{3}-\mathrm{C}_{\mathrm{z}}$, and $\mathrm{C}_{\mathrm{z}}-\mathrm{C}_{4}$ channels, $0.63,0.76,0.67,0.70,0.69$, and 0.75 , respectively). (For beta frequencies, $p<0.05$ in $\mathrm{Fp}_{2}-\mathrm{C}_{4}, \mathrm{C}_{3}-\mathrm{C}_{\mathrm{z}}$, and $\mathrm{C}_{\mathrm{z}}-\mathrm{C}_{4}$ channels and $p<0.001$ in $\mathrm{C}_{3}-\mathrm{O}_{1}$ and $\mathrm{C}_{4}-\mathrm{O}_{2}$ channels; for amplitude and theta, alpha, and delta frequencies in all channels, $p<$ 0.001 ). Figures $1-3$ show the correlation between the bilirubin levels and amplitude and delta and theta frequencies of $\mathrm{Fp}_{1}-\mathrm{C}_{3}$ channel.

In terms of the vertex, $\mathrm{k}$ complex, and sleep spindle, there were no differences between both groups in the third month $(p$ $>0.05)$.

\section{DISCUSSION}

Jaundice is one of the major problems of newborns in Turkey (11). Reversible depressive effects of bilirubin on neuronal functions were shown with modern neurophysiologic diagnostic techniques such as brainstem evoked potentials, visual evoked potentials, somatosensory evoked potentials, and cry analysis (11-15).

Bilirubin especially affects the thalamus and cerebral cortex. Because rhythmic oscillations on the EEG arise from the interaction between the cortex and thalamus, the electrophysiologic effects of bilirubin on the rhythmic oscillations during 


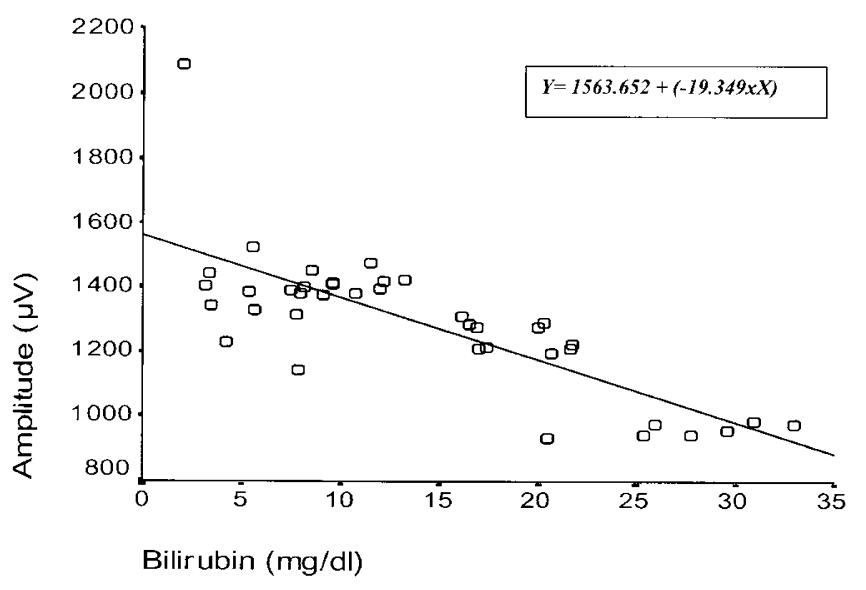

Figure 1. Correlation between bilirubin levels and amplitudes.

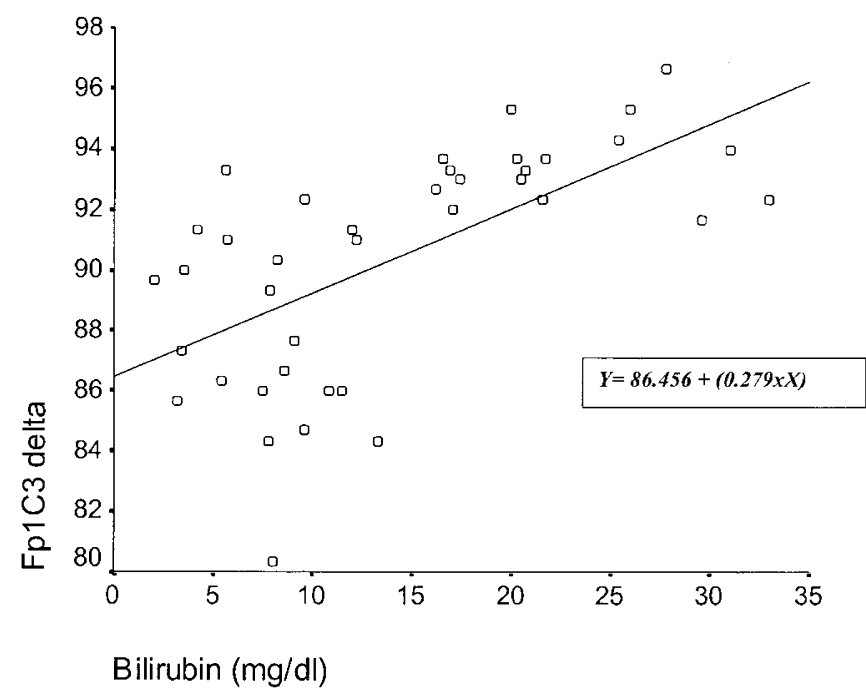

Figure 2. Correlation between bilirubin levels and $\mathrm{Fp}_{1}-\mathrm{C}_{3}$ delta frequency.

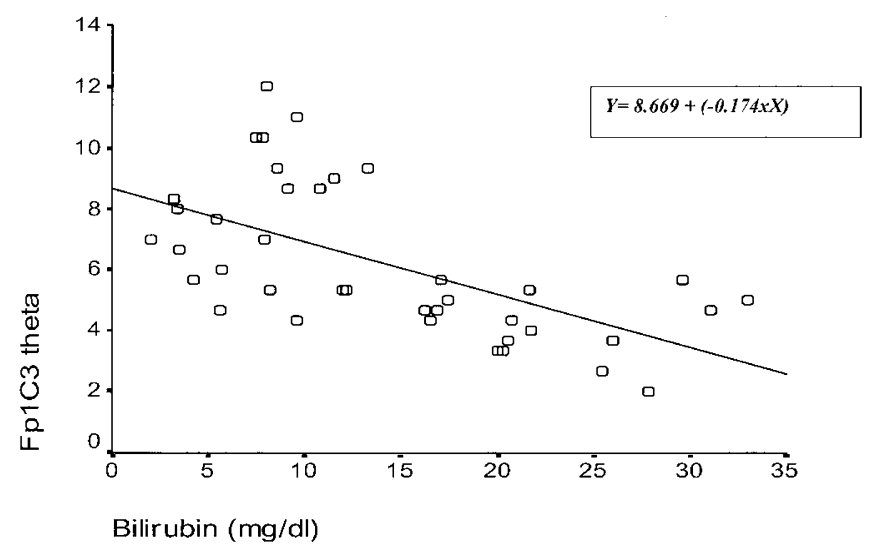

Figure 3. Correlation between bilirubin levels and $\mathrm{Fp}_{1}-\mathrm{C}_{3}$ theta frequency.

long-term postnatal age were investigated. Only one study is available on the effects of bilirubin on the EEG (16). In the study by Wennberg and Hance in 1986 (16), unilateral bilirubin encephalopathy was designed experimentally on rats, and decreased amplitudes and flattening of the EEG waves were observed. The EEG served as an indicator of developing encephalopathy. The EEG changes were best predicted by the degree of blood-brain barrier opening and by the quality of serum bilirubin binding.

The EEG is an excellent method for measuring brain maturation in newborns $(7,17)$. By showing the development of electrical maturation of the brain, early diagnosis of brain damage on high-risk infants is possible (7). For this reason, many studies have been conducted in preterm and term babies $(7,18)$. As a result, the delay of brain maturation can be detected earlier and at the same time determination of prognosis and brain damage can be detected.

Transient delay in the EEG brain maturation was shown in high-risk infants, such as Down syndrome, bronchopulmonary dysplasia, respiratory distress syndrome, and intraventricular hemorrhage, and in babies of preeclamptic and diabetic mothers (19-23). It has been proven by evoked potentials that hyperbilirubinemia has suppressive effects on neuronal functions but there is no study about the effect of hyperbilirubinemia on EEG maturation. In our study, we have used EEG frequencies and amplitudes as a marker of bilirubin toxicity $(16,24)$. We have found that the amplitude during jaundice in the study group was markedly lower than that in the control group. We have seen a $20 \%$ decrease in the amplitude levels in the study group. In the study group with normal bilirubin levels the amplitude levels were similar to those of the control group in the EEG investigations on the 15th $\mathrm{d}$. We have shown that the amplitude of EEG has been affected by the bilirubin levels and decreased with increasing bilirubin levels and also this effect has not been seen with normal bilirubin levels. We had thought that the effect of bilirubin on the amplitude was dose dependent and reversible and has a short interval as on the brainstem evoked potential $(11,12)$.

High slow-wave frequencies during the newborn period, decrement of these frequencies with age, and an increase of rapid frequencies are markers of brain maturation $(17,18$, 25-27). In our study, delta activity was the major frequency component. We found that delta frequency in the study group was significantly higher than in the control group and this activity decreased with age in both groups. On the other hand, theta frequency was less in the study group than in the control group. The theta frequency increased with age. This may be caused by the effect of bilirubin on neuronal functions. The data showed that hyperbilirubinemia without clinical symptoms caused electrophysiologic changes of cerebrocortical activity in the brain.

In our study, hyperbilirubinemia also caused transient delay in brain maturation. The difference of the delta frequency disappeared in the first month in the central $\left(\mathrm{Cz}-\mathrm{C}_{4}\right)$ and right posterior regions $\left(\mathrm{C}_{4}-\mathrm{O}_{2}\right)$ and in the left posterior $\left(\mathrm{C}_{3}-\mathrm{O}_{1}\right)$ and right anterior regions $\left(\mathrm{Fp}_{2}-\mathrm{C}_{4}\right)$ in the third month However, the difference persisted in the left anterior $\left(\mathrm{Fp}_{1}-\mathrm{C}_{3}\right)$ region during the third month. We observed that the difference of the theta frequency disappeared in the central $\left(\mathrm{Cz}-\mathrm{C}_{4}\right)$, right posterior $\left(\mathrm{C}_{4}-\mathrm{O}_{2}\right)$, and left anterior regions $\left(\mathrm{Fp}_{1}-\mathrm{C}_{3}\right)$ in the first month. It disappeared in the third month in the right anterior $\left(\mathrm{Fp}_{2}-\mathrm{C}_{4}\right)$ and left posterior $\left(\mathrm{C}_{3}-\mathrm{O}_{1}\right)$ regions. Inasmuch as there is less neuronal connectivity in other head regions, in contrast to greater connectivity in central regions (28), we detected that 
the suppressive effect of bilirubin on the cerebrocortical activity lasts for a far shorter period in the central region whereas it lasts longer in the anterior regions.

There were no differences between the two groups in terms of vertex, sleep spindle, and $\mathrm{k}$ complex in the third month, which supported the hypothesis that hyperbilirubinemia caused transient delay in the brain maturation.

We conclude that hyperbilirubinemia affects the cerebrocortical electrical activity, but appears to be time limited.

\section{REFERENCES}

1. Whitington PF, Gartner LW 1993 Disorders of bilirubin metabolism. In: Nathan DG, Oski FA (eds) Hematology of Infancy and Childhood. WB Saunders, Philadelphia, pp 74-114

2. Oski FA 1991 Disorders of bilirubin metabolism. In: Taeusch HW, Ballard RA, Avery ME (eds) Diseases of the Newborn. WB Saunders, Philadelphia, pp 749-777

3. Kliegman RM 1996 Jaundice and hyperbilirubinemia in the newborn. In: Nelson WE, Behrman RE, Kliegman RM, Arvin AM (eds) Textbook of Pediatrics. WB Saunders, Philadelphia, pp 493-499

4. Hansen TWR, Bratlid D 1986 Bilirubin and brain toxicity. Acta Pediatr Scand 75:513-522

5. Gartner LM, Snyder RN, Chabon RS, Bernstein J 1970 Kernicterus: high incidence in premature infants with low serum bilirubin concentrations. Pediatrics 45:906-917

6. Morphis L, Constantopoulos A, Matsanıtıs N 1982 Bilirubin-induced modulation of cerebral protein phosphorylation in neonate rabbits in vivo. Science 218:156-158

7. Tharp BR 1990 Electrophysiological brain maturation in premature infants: an historical perspective. J Clin Neurophysiol 7:302-314

8. Dubowitz L, Dubowitz V, Goldberg C 1970 Clinical assessment of gestational age in the newborn infant. J Pediatr 77:1-10

9. Robertson WO 1998 Personal reflections on the AAP practice parameter on management of hyperbilirubinemia in the healthy term newborn. Pediatr Rev 19:75-77

10. Jasper HH 1958 The ten-twenty electrode system of the International Federation. Electroencephalogr Clin Neurophysiol 10:371-373

11. Özmert E, Erdem G, Topçu M, Yurdakök M, Tekinalp G, Genç D, Renda Y 1996 Long-term follow-up indirect hyperbilirubinemia in full-term Turkish infants. Acta Paediatr 85:1440-1444
12. Nakamura H, Takada S, Shimabuku R, Matsuo M, Matsuo T, Negishi H 1985 Auditory nerve and brainstem responses in newborn infants with hyperbilirubinemia. Pediatrics 75:703-708

13. Koivisto M 1987 Cry analysis in infants with Rh haemolytic disease. Acta Paediatr Scand 335:1-73

14. Chen YJ, Kang WM 1995 Effects of bilirubin on visual evoked potentials in term infants. Eur J Pediatr 154:662-666

15. Bongers-Schokking B, Colon EJ, Hoogland RA, Van den Brande JL, Groot CJ 1990 Somatosensory evoked potentials in neonatal jaundice. Acta Pediatr Scand 79:148155

16. Wennberg RP, Hance J 1986 Experimental bilirubin encephalopathy: importance of total bilirubin, protein binding, and blood-brain barrier. Pediatr Res 20:789-792

17. Szeto H 1990 Spectral edge frequency as a simple quantitative measure of the maturation of electrocortical activity. Pediatr Res 27:289-292

18. Scher MS, Sun M, Steppe DA, Guthrie RD, Sclabassi RJ 1994 Comparisons of EEG spectral and correlation measures between healthy term and preterm infants. Pediatr Neurol 10:104-108

19. Ellingson RJ, Peters JF 1980 Development of EEG and daytime sleep patterns in trisomy-21 infants during the first year of life: longitudinal observations. Electroencephalogr Clin Neurophysiol 50:457-466

20. Hahn JS, Tharp BR 1990 Winner of the Brazier Award: the dismature EEG pattern in infants with bronchopulmonary dysplasia and its prognostic implications. Electroencephalogr Clin Neurophysiol 76:106-113

21. Tharp B, Scher M, Clancy R 1989 Serial EEGs in normal and abnormal infants with birth weights less than 1200 grams: a prospective study with long term follow-up. Neuropediatrics 20:64-72

22. Haas GH, Prechtl HF 1977 Normal and abnormal EEG maturation in newborn infants. Early Hum Dev 1:69-90

23. Schulte FJ, Michaelis R, Nolte R, Albert G, Parl U, Lasson U 1969 Brain an behavioral maturation in newborn infants of diabetic mothers. I. Nerve conduction and EEG patterns. Neuropaediatrie 1:24-35

24. Holmes GL, Lombroso CT 1993 Prognostic value of background patterns in the neonatal EEG. J Clin Neurophysiol 10:323-352

25. Ktonas PY, Fagioli I, Salzarulo P 1995 Delta $(0.5-1.5 \mathrm{~Hz})$ and sigma $(11.5-15.5 \mathrm{~Hz})$ EEG power dynamics throughout quiet sleep in infants. Electroencephalogr Clin Neurophysiol 95:90-96

26. Parmelee AH 1969 EEG power spectral analysis of newborn infants' sleep states. Electroencephalogr Clin Neurophysiol 27:690-691

27. Schulte FJ, Bell EF 1973 Bioelectric brain development: an atlas of EEG power spectra in infants and young children. Neuropaediatrie 4:30-45

28. Thatcher RW, Walker RA, Gludice S 1987 Human cerebral hemispheric development at different rates and ages. Science 236:1110-1113

\section{Erratum}

In the article "Gamma-Linoleic Acid and Ascorbate Improves Skeletal Ossification in Offspring of Diabetic Rats" (Pediatr Res 51:647-652, 2002), the acknowledgments on p. 651 read "... This paper is dedicated to the memory of our friend and colleague Dr. Ruth Garland." It should read “. . . This paper is dedicated to the memory of our friend and colleague Dr. Hugh O. Garland." The publisher regrets this error. 